\title{
Practice and Innovation of Labor Education in Guangdong Higher Vocational Colleges: Connotation, Status, Dilemma and Paths
}

\author{
Weibo Qiu ${ }^{1, *}$ Penghao $\mathrm{Li}^{1}$ Xinying $\mathrm{Li}^{1}$ Xiaoling Liu ${ }^{1}$ \\ ${ }^{1}$ Guangdong Nanhua Vocational College of Industry and Commerce, Guangzhou, Guangdong, China \\ *Corresponding author. Email: 593920797@qq.com
}

\begin{abstract}
At present, the phenomenon of weakening of labor education in higher vocational colleges still exists, which is prominently reflected in the lack of labor opportunities, lack of labor awareness, weak labor ability, short working hours, superficial labor cognition, and single form of labor education, leading to the phenomenon of students neglecting labor, rejecting labor, and not cherishing the results of labor, which is far from the requirements for the comprehensive development of morality, intelligence, physical education, art, and labor. This project uses empirical research methods and takes students from higher vocational colleges in Guangdong as the research object to explore the connotation and status of labor education in the context of the new era, the main dilemmas faced and solutions. The project has obtained 1121 valid samples and 5 interview samples. After data analysis, the following conclusions are drawn: First, most students lack labor awareness and have not established correct labor values. (1) Half of the students have relatively short working hours; (2) More than half of the students believe that labor has a punitive meaning; (3) Some students are more utilitarian in labor; (4) Nearly half of the respondents have superficial work cognition; Second, the school's labor teaching system is not comprehensive, and the curriculum is not smoothly launched. (1) The teaching method is dull and boring, and some schools do not combine theoretical education with practical education; (2) At present, there are problems such as single form of labor education in higher vocational education; (3) There is no clear teaching purpose. Based on data analysis and discussion, the project team made the following suggestions: The first is to improve the school's labor curriculum system and increase the resource input of labor education; the second is to cultivate the emotional foundation of labor education; the third is to establish a sound labor education management system.
\end{abstract}

Keywords: Higher vocational colleges, Labor education, Dilemma, Solution paths.

\section{INTRODUCTION}

\subsection{Raise of the Questions}

In September 2018, General Secretary Xi Jinping proposed at the National Education Conference: Socialist education should cultivate socialist builders and successors who have a

*Project: Result of 2021 Guangdong Province Science and Technology Innovation Strategy Special Fund ("Climbing Plan" Special Fund) General Project (Project No.: pdjh2021b0857); Phrased result of 2021 Guangdong Nanhua Vocational College of Industry and Commerce School-level Scientific Research Project (Labor Education Special Project) (No. 2021LD03, 2021LD09). comprehensive development of morality, intelligence, physical education, art, and labor. He gave a comprehensive elaboration on the education policy of China, which enriched the connotation of the education policy and made the goal of the education policy for educating people more comprehensive. On March 20, 2020, the Central Committee of the Communist Party of China and the State Council issued the "Opinions of the Central Committee of the CPC and the State Council on Comprehensively Strengthening Labor Education in Universities, Middle Schools and Primary Schools in the New Era". The "Opinions" emphasizes that "labor education is an important part of the socialist education system with Chinese 
characteristics. It is necessary to fully implement the party's education policy, adhere to strengthening moral education and cultivating people, and incorporate labor education into the entire process of talent training." As a result, labor education has attracted great attention and active practice by universities, middle schools and primary schools, including higher vocational colleges. Guangdong higher vocational colleges also stand in the trend of the times, vigorously promote labor education into schools and classrooms, and gradually explore a batch of experience and practices that have promotion significance and demonstration effects. At the same time, the current weakening of labor education in higher vocational colleges still exists, which is prominently manifested in aspests of the lack of labor opportunities, lack of labor awareness, weak labor ability, short working hours, superficial labor cognition, and single form of labor education, leading to the phenomenon of students neglecting labor, rejecting labor, and not cherishing the results of labor, which is far from the requirements for the comprehensive development of morality, intelligence, physical education, art, and labor

Therefore, this project uses empirical research methods, mainly questionnaire surveys, supplemented by case interviews, with students from Guangdong vocational colleges as the research object, and conducts targeted investigations on the attitudes and opinions of students in Guangdong vocational colleges on labor education, the status quo of labor education in higher vocational colleges, and the difficulties and problems existing in labor education. Project personnel draw scientific conclusions on the basis of data analysis, and put forward specific solutions and measures to provide more effective, more systematic, and more targeted countermeasures and suggestions for labor education in Guangdong and even the whole country, and help the improvement of vocational students' labor literacy and overall quality.

\subsection{Definition of Related Concepts}

\subsubsection{The Basic Connotation of Labor Education}

Traditional work can be divided into physical work and mental work. Physical work is main body movement that mainly based on the movement of human muscles and bones, and supplemented by the brain and other physiological systems. And mental work refers to the main body movement that mainly carried out by the movement of the brain and nervous system, and supplemented by other physiological systems. At present, labor education in Chinese higher vocational colleges is mostly manual labor, lacking systematic theoretical teaching and labor concept training, and the teaching form and content are relatively simple.

\subsubsection{The Concept Extension of Labor Education}

Labor is closely related to human daily activities and the development of social laws. Ren Ping and He Yang (2020) mentioned that German "general vocational education" links vocational skills teaching with economics, science and technology, and integrates vocational education and labor education, forming a systematic and complete form of labor education; at the same time, labor education should also include the cultivation of labor concepts, so that students can establish a correct and complete labor view, and be cultivated into builders and successors for the development of socialism in the comprehensive development of morality, intelligence, physical education, art, and labor

\subsection{Current Research Status in China and Foreign Countries}

Compared with China, the research on labor education in foreign countries started earlier. In the exploration and practice, labor education powers with the United States, the United Kingdom, Germany, and Japan as the main representatives have also been formed. British economist Bayless first clearly proposed the combination of education and manual labor. British vocational schools mainly introduced production labor into the education field through the "social participatory learning model" to promote education to adapt to social and economic development; U.S. labor education research is represented by Dewey, Parker, Kerberch, etc., advocates "student-centered", advocates "learning by doing", and combines education with productive labor, which eliminates the gap between education and labor to a certain extent, making education face real life and serve social production; Japan's labor education system has been established, forming a complete education system from kindergarten to university. The focus is to allow students to fully free their hands, complete labor tasks, develop labor habits, experience labor production, improve self-labor literacy, change their thinking and understanding, and improve labor personality. In 
the long-term practice, foreign labor education research has embodied the characteristics of early start, sufficient theoretical research, and sufficient practical experience cases. It has formed a relatively mature theoretical support system and labor education curriculum support system, which is worthy of our reference.

In terms of research in China, the researchers conducted a search under the title of "Labor Education in Higher Vocational Colleges" and obtained a total of 120 documents in CNKI, of which only 2 academic papers were published in core journals in the past three years. Through reading, researching and summarizing the literature, the summary is as follows:

\subsubsection{Research on Connotation and Practical Significance}

Hu Junjin, Tan Chuanbao (2018), Cheng Dehui (2019) analyzed the positive influence of Marxist labor values and labor education view on higher education in the new era; Jiang Lijun (2019) analyzed the important relationship between the theoretical connotation of labor education and practice; Zhao Zaojun (2020), Zhang Jie, Wen Chengfang (2019), and Li Ying (2020) discussed the necessity and importance of the spiritual integration and development of college labor education and college students in the new era.

\subsubsection{Research on Problems and Countermeasures}

Wang Xuhong (2011), Su Zhouyuan (2015), Wang Wei (2019), Zhang Jian (2019) carried out research on problems and countermeasures in labor concept, labor evaluation, labor education value, etc.; Che Lina, Deng Haiyun (2020), Zhang
Taohong (2011) focused on the research on cognitive deviations of labor concepts and related countermeasures; Gao Yaqin (2010) focused on the practical research of college students' humanistic quality education; Zhao Zhangbin (2020) focused on innovative research on labor education in higher vocational colleges in the new era.

\subsubsection{Research on the Construction of the System}

Gao Yong (2019) proposed a labor education system for college students with the "three comprehensives" labor education from the perspective of the new era; Wang Shengyu and $\mathrm{Wu}$ Yujian (2018) focused on the construction of a multi-party craftsman spirit cultivation and labor education system; Yang Xiaohui and Huang Junlu (2019) emphasized on exploring the construction of labor aesthetic education system in higher vocational colleges.

\subsubsection{Foreign Research Inspiration}

Li Zhen (2012) and Sun Jinchao (2019) put forward their own enlightenment for college labor education based on the research of Soviet labor education thought; Fu Xiaofang and Zhou Li (2005) focused on the comparison of the status quo of labor technology in Germany and China, and put forward the enlightenment for labor education in China; Zhang Xi, Yuan Yuzhi, and Li Haibo (2019) put forward their own countermeasures and suggestions based on international experience and actual conditions in China.

The comparison of labor education in China and foreign countries is shown in the following "Table $1 "$.

Table 1. Comparison of labor education in China and foreign countries

\begin{tabular}{|l|l|l|}
\hline Differences & \multicolumn{1}{|c|}{ China } & Foreign countries \\
\hline $\begin{array}{l}\text { Course } \\
\text { content }\end{array}$ & $\begin{array}{l}\text { 1. Emphasis on education in theoretical, macroscopic } \\
\text { view of labor and world view. } \\
\text { 2.The separation of vocational guidance and labor } \\
\text { curriculum teaching. }\end{array}$ & $\begin{array}{l}\text { 1. A teaching method that emphasizes specific and } \\
\text { practical guidance. } \\
\text { 2. The integration of vocational guidance and labor } \\
\text { education. }\end{array}$ \\
\hline Faculty & $\begin{array}{l}\text { Most teachers of other subjects are part-time or ons } \\
\text { transferred to teach courses. }\end{array}$ & $\begin{array}{l}\text { There is a professional teacher training system and } \\
\text { a professional labor education concept. }\end{array}$ \\
\hline $\begin{array}{l}\text { Teaching } \\
\text { objectives }\end{array}$ & $\begin{array}{l}\text { There is no systematic teaching system, only simple } \\
\text { physical labor, and students are not clear about the } \\
\text { purpose of labor education. }\end{array}$ & $\begin{array}{l}\text { There is a systematic "general vocational } \\
\text { education" system, aiming to achieve the fusion and } \\
\text { integration of academic education and vocational } \\
\text { and technical education in the curriculum system. }\end{array}$ \\
\hline $\begin{array}{l}\text { Similarities: The teaching content is similar to that of higher vocational education, and both have vocational education planning } \\
\text { and teaching. }\end{array}$ \\
\hline
\end{tabular}


To sum up, the researchers conduct empirical investigations on the status and difficulties of the development of labor education in higher vocational colleges in Guangdong, the cultivation of higher vocational students' labor awareness, the development of labor education curriculum system, and the attitudes and views of higher vocational students on labor education, to look for the main problems and drawbacks, combine literature research and data analysis, and then give practical countermeasures and suggestions, which have very important theoretical and practical significance.

\section{OVERVIEW OF THE SURVEY}

\subsection{Survey Object and Content}

- $\quad$ Survey Time

September-December 2020

- Survey Method

Questionnaire survey plus interview

- Survey Object

Students from higher vocational colleges in Guangdong Province

- Survey Content

1. Understanding of the connotation and status of labor education: Including the attitudes, views, and understanding of labor education of college students in higher vocational schools, and their understanding and attention to the connotation and status of labor education;

2. Cognition and suggestions on labor education dilemmas: including the dilemmas faced by labor education in higher vocational colleges and student suggestions;

3. Proposing solutions to the dilemma of labor education.

\subsection{Survey Methods and Tools}

- $\quad$ Self-filled questionnaire method

Using the self-made questionnaire "On the Practice and Innovation of Labor Education in Higher Vocational Colleges in Guangdong: Questionnaire on Connotation, Status, Dilemma and Path", the questionnaire was released on the questionnaire star.
- Interview method

Conduct interviews on the basis of self-made "Interview Outline for the Ideas of People Related to Labor Education".

\subsection{Sample Recovery Situation}

The survey collected a total of 1121 questionnaires, of which 1121 were valid questionnaires, with an effective rate of $100 \%$. They were mainly carried out using software such as SPSS17.0, EXCEL2010, WORD2010, and finally analyzed and expressed in the form of figures, tables, and texts.

\section{DATA ANALYSIS}

\subsection{Basic Analysis of the Questionnaire}

\subsubsection{Analysis of Daily Working Hours}

Data show that in this survey, $50.13 \%$ of the respondents work at home within one hour a day, and $35.68 \%$ of the respondents work at home for one to two hours a day. The data shows that most students usually do daily labor, but the labor time is not long.

\subsubsection{Analysis of the Necessity of Carrying out Labor Education}

The data show that $39.07 \%$ of the respondents believe that it is necessary to carry out labor education in higher vocational colleges; $33.81 \%$ of the respondents believe that it is necessary to carry out labor education, but do not like it; $19.00 \%$ of the surveyed people do not care about the labor education in higher vocational colleges, and they are all okay with any conditions. The data show that most students agree with the development of labor education courses and also show that they understand the importance of labor education. However, due to the single school development method, students lose interest and motivation to study labor education courses; in addition, a small number of students do not understand the significance of labor education, and schools should increase guidance on the significance of labor education. 


\subsubsection{Analysis of the Degree of Interest in Labor Education}

The data show that $69.30 \%$ of the respondents are generally interested in the labor education carried out by their school, $16.20 \%$ are not interested, and $13.40 \%$ are very interested. The data show that the labor education carried out by most schools is not interesting enough to arouse students' interest in learning. The reason may be that the labor education courses carried out by the schools are relatively simple and boring, which makes the students' interest degree not high, and only a small part of students are very interested in the labor education carried out by the school. Therefore, schools should change their teaching thinking, pay more attention to students' interest in learning, and change or enrich labor teaching methods in order to better guide students to actively participate in labor, thereby cultivating students' correct outlook on labor.

\subsubsection{Analysis of the Quality of Labor Courses}

The data show that $52.70 \%$ of the respondents believe that the labor education curriculum of their school only carries a simple labor model without special courses; $33.30 \%$ of the respondents believe that there is a combination of relevant labor curriculum training and offline labor; $8.80 \%$ of the respondents think that there are related labor courses, but the focus of the courses is biased, and they think that they pay too much attention to technology and ignore the students' interests. The data show that the labor education carried out by most schools only stays in a simple mode, and there is no special curriculum, and there is a lack of theoretical guidance. The popularization of labor education theory can better help students understand labor education, and practical activities can help students increase their interest. Therefore, labor education should be a combination of practice and theory.

\subsubsection{Analysis of Teaching Methods Suitable for Labor Education}

The data show that $62.70 \%$ of the respondents believe that "practical teaching is the mainstay and theoretical teaching is supplemented" is suitable for labor education teaching methods; $17.90 \%$ of the respondents believe that "theoretical teaching is the mainstay and practice teaching is supplemented" is a suitable teaching method for labor education;
$14.20 \%$ of the surveyed believe that students can organize and arrange labor activities on their own. The data show that compared to learning theoretical knowledge in the classroom, students are more interested in hands-on practice, but only practical teaching without theoretical teaching guidance is not conducive to cultivating students' labor values.

\subsubsection{Analysis of the Reflection of Important Position of Labor Education}

The data show that $73.20 \%$ of the respondents believe that labor education can grasp the direction of education, improve the overall quality of students, and promote the overall development of students; $66.90 \%$ of the respondents believe that labor education follows the laws of education, strengthen practical experience, let students experience the labor process, and improve the effectiveness of education; $66.70 \%$ of the respondents believe that labor education reflects the characteristics of the times, strengthens labor awareness, and improves creative labor ability. The data show that most respondents believe that the important position of labor education in the education system is mainly reflected in "grasping the direction of education, improving the overall quality of students, and promoting the overall development of students", "following the law of education, strengthening practical experience, letting students experience the labor process, and improving the effectiveness of educating people" and other aspects. At the same time, it also reflects the recognition of the important status of labor education in the hearts of students in higher vocational colleges.

\subsubsection{Analysis of the Mean and Standard Deviation of the Degree of Understanding of Labor Education and the Degree of Attention}

The data show that in the survey respondents' understanding and attention to labor education, the average value of "connotation of labor education" is the highest (2.51), and the lowest is "meaning of labor" (2.39), and the standard deviation between the two is relatively small. It shows that most respondents occasionally pay attention to the connotation and significance of labor education and have a general understanding, which further proves the necessity and urgency of labor education in higher vocational colleges. 


\subsubsection{Analysis of the Main Reasons for the Lack of Labor Concept}

The data show that among the main reasons for the lack of labor concepts among college students, $68.00 \%$ of the respondents chose personal laziness as the first option, and $27.90 \%$ of the respondents chose parental indulgence as the second option. The data show that most respondents believe that the main reason for the lack of labor concept is personal laziness, followed by parental indulgence. There are also some respondents who believe that deviations in labor concepts are also the main reason, which shows that higher vocational colleges and families need to work together to guide students to establish correct labor values.

\subsubsection{Analysis of Labor Ability Required for Future Employment}

The data show that $51.70 \%$ of the respondents choose innovation ability as their first choice, $29.30 \%$ choose logical thinking ability as the second choice, and $19.40 \%$ choose learning ability as their third choice. The data show that most students think that innovation ability, logical thinking ability, and learning ability are very important in future employment; at the same time, a small number of students think that social skills, practical skills, and teamwork skills are more important. Therefore, schools should move closer to these directions when setting labor teaching skills goals, which is more conducive to cultivating students' interest in labor and stimulating students' learning enthusiasm.

\subsubsection{Analysis of the Main Problems in Labor Education}

The data show that $61.10 \%$ of the respondents believe that the current higher vocational labor education lacks a complete labor education system, $52.50 \%$ of the respondents believe that there is a lack of practicality, and $51.00 \%$ of the respondents believe that there is a problem of insufficient resource input. The data shows that over $60 \%$ of the surveyed believe that higher vocational colleges lack a complete labor education system, which makes it difficult to implement labor education courses in practice.

\subsubsection{Analysis of Ways to Solve Problems in Labor Education}

The data show that $64.60 \%$ of the respondents believe that perfecting the labor education curriculum system can solve the problems of labor education, $51.90 \%$ of the respondents believe that the establishment of a labor education management system can solve the problems, and $46.30 \%$ of the respondents believe that increasing the input of labor resources can solve the problem. The data show that most students believe that the need to improve the labor education curriculum system is more conducive to the implementation of labor education on campus; therefore, the school should systematically arrange for students to study labor education, so as to cultivate students to form correct labor concepts.

\subsubsection{Analysis of the System That Is More Conducive to Stimulating Students' Interest in Labor}

The data show that $41.20 \%$ of the respondents choose the reward system as the first option, and the school stipulates that people who reach a certain working hours and outstanding each year will be rewarded; $30.60 \%$ of the respondents choose the reward system as the second option; $23.10 \%$ of the respondents took the evaluation system as the third option, combining the students' participation in labor education with social practice courses and comprehensively evaluating the assessment. The data show that most of the respondents believe that the reward system is more conducive to stimulating students' interest in labor and increasing their enthusiasm for labor.

\subsection{Cross-analysis of Questionnaires}

\subsubsection{Cross-analysis of the Degree of Interest in the Labor Education Carried out and the Quality of Labor Education Courses}

The researchers cross-analyze the degree of interest in labor education carried out by the school and the quality of labor education courses in the school, $\mathrm{P}=0.00<0.05$. The data show that most of the respondents are generally interested in the quality of the courses in their school, which is above $50.00 \%$, and the proportion of those who are very interested in the quality of the school's labor education courses is about $10.00 \%$. On the whole, 
the improvement of the quality of labor education courses is conducive to increasing students' interest in labor courses.

\subsubsection{Cross-analysis of Teaching Methods Suitable for Labor Education and the Quality of School Labor Education Courses}

The researchers cross-analyze how the quality of labor education courses in the school and what teaching methods people think are suitable for labor education, $\mathrm{p}=0.001<0.05$. Data show that with the enrichment and development of labor education methods, the higher the quality of the courses. However, most vocational colleges only have a simple labor education model, do not have a complete teaching system, and are different from students' ideal teaching methods. It can be seen that schools should find suitable teaching methods based on actual conditions, formulate a scientific labor education curriculum system, and stimulate students' interest in participation and learning, so as to improve the quality and level of labor education.

\section{SUMMARY}

Firstly, most students lack labor awareness and have not established correct labor values.

- Half of the students have shorter labor hours on average. The survey data show that the current daily working hours of most vocational students are less than one hour, the working hours are relatively short, and the working awareness, working conditions, and working opportunities are relatively lacking.

- More than half of the students believe that labor has a punitive meaning. With the rapid development of technology and economy in society, more people are accustomed to mental work, and they have a sense of resistance to manual work. When physical work is done involuntarily, the notion that labor is punitive will arise.

- Some students' labor is more utilitarian. According to the data in question 17 of the questionnaire, the first purpose of most students' labor is to obtain remuneration, which is easy to form "money worship" values, and thus ignore the spiritual value, which is in contrast to the party and the state's positioning and expectations for higher vocational education and the needs of social production.
- Nearly half of the respondents have superficial work cognition. In the current society and schools, the hierarchical distinction between high and low labor, the contempt and contempt for manual labor, and the misunderstanding and dwarfing of school labor education have caused that students in higher vocational colleges have cognitive misunderstandings and practical shortcomings in labor attitudes, labor concepts and labor skills, which is not conducive to the implementation and development of labor education.

Secondly, the school's labor teaching system is not comprehensive, and the curriculum is not smoothly launched.

At present, the higher vocational colleges in Guangdong Province are currently gradually advancing the labor education reform in depth, but the school labor education system has not been comprehensively improved. Through data analysis and research on interview materials, the following major problems have been found:

- The teaching method is dull and boring. Some schools do not combine theoretical education with practical education. Only through theoretical teaching will make students lose interest in labor education courses. On the contrary, if the school only conduct practical teaching and ignore theoretical teaching, there will be no clear teaching goals, which will easily make students lose their learning direction. Neither of them can achieve the teaching goals required by the party and the state.

- At present, the labor education in higher vocational colleges has prominent problems such as the single form of labor education, the teaching methods are not diverse enough, the teaching mode is single and rigid, the teaching content and form are not innovative, and the students' enthusiasm for learning cannot be mobilized, which directly leads to the decline of the quality of labor education.

- There is no clear teaching purpose. When teaching in some higher vocational colleges, they did not clearly inform the students of the purpose of teaching, and only performed a single manual labor. The students stayed in a state of "knowing what is happening and not knowing why". This will only double the effort and achieve the expected results. 


\section{COUNTERMEASURES AND SUGGESTIONS}

\subsection{Improving the School's Labor Curriculum System and Increasing Resource Input in Labor Education}

As far as the current situation of labor education in higher vocational colleges is concerned, the main problems are: the educational philosophy is eager for quick success and instant benefits, and lacks down-to-earth pragmatism; the training objectives are vague and lack the certainty of the program; the training system is illusory and lacks the feasibility of implementation; the education method is boring and single, and lacks lively life. In order to solve these problems, higher vocational colleges should clarify the following points when formulating and improving the labor education system:

\subsubsection{Establishing Four Core Value Goals}

It is necessary to cultivate a noble and great concept of glorious labor, cultivate a concept of hard work, promote a down-to-earth concept of honest labor, shape a pioneering and innovative scientific concept of labor, establish correct labor values from the theoretical knowledge that students can easily accept and attach the "first button" of labor education so that it can be more conducive to the implementation of subsequent practical courses.

\subsubsection{Exploring the "Four-in-one" Approach to Practice Education}

Higher vocational colleges should gradually build a labor education practice education path with the dimensions of experience, employment, participation and survival, integrate labor and practice into curriculum teaching, let students experience the meaning of labor, increase experience in the application of theoretical knowledge, and ultimately achieve the teaching goal of applying what has been learned.

\subsubsection{Realizing the Working Mechanism of "Three All-round Education" in Labor}

In the process of labor education in higher vocational colleges, it is possible to introduce the concept of "full-staff, full-process, and all-round" education in ideological and political education, and continuously improve teaching concepts, teaching methods and teaching purposes, forming a joint force in education and teaching to jointly promote the improvement of the quality and level of labor education in higher vocational colleges.

\subsection{Cultivating the Emotional Foundation of Labor Education}

First, leading by government departments, it is necessary to strengthen the purification, supervision and guidance of online public opinion and mass media platforms, pay attention to the social promotion of the deeds of advanced characters and the spirit of model workers, and create a cultural atmosphere that takes pride in hard work and shame in pleasures and dislikes. Particular attention should be paid to the introduction of model workers and craftsmen from major countries to part-time labor education instructors in higher vocational colleges to cultivate the spirit of labor, craftsmanship, and model labor of students.

Second, in the construction of campus culture, it will be a must to do a good job of labor education, not only focus on the learning of students' labor knowledge and skills, but also help students to improve their personality and cultivate good ideological and moral qualities through labor, creating a good working culture atmosphere through the guidance of theoretical education and the actions of practical education.

Third, in family education, students should be the driven force of the change of family concepts. Schools can arrange homework related homework content to promote the atmosphere of family labor and encourage elders to abandon the doting education of children. Schools should also maintain communication with families, change parents' narrow understanding and cognition of labor, correctly view and evaluate the relationship between physical labor and mental labor, change the way of housekeeping parenting, and guide children to gradually form labor concepts in family life and their sense of responsibility for family affairs.

\subsection{Establishing a Sound Labor Education Management System}

\subsubsection{Teacher Level Management}

Germany's labor education has a long history of development and has a complete labor education system. Through comparison, it is found that China's labor education professional teacher training is relatively scarce, and the public's awareness is relatively weak. German labor 
education lecturers need six years of teacher education and on-the-job training from time to time, which greatly improves the level of labor education teachers; In China, labor education lecturers are mostly part-time teachers or transferred teachers in other disciplines, and their professionalism is slightly weak. Therefore, to improve the quality and level of labor education in higher vocational colleges, the key point is to cultivate a team of high-level, high-quality and high-skill labor education teachers. It is of great significance to further strengthen the training of labor education teachers, encourage them to carry out advanced studies and other special training, continuously optimize the structure of the teaching staff, and improve the overall level of the teaching staff.

\subsubsection{Education System Management}

Through various studies, it has been found that the content of labor teaching in higher education institutions in Germany is similar to that of my country's higher vocational education. However, when teaching in Germany, the integration of vocational education and labor concept education has enabled students to receive a comprehensive and systematic labor education; However, China separates vocational education from labor education, and labor education lacks theoretical teaching, which causes the problems of unclear labor education concepts and fuzzy labor concepts among students in China. Therefore, higher vocational colleges should explore the establishment of a consistent labor education system, smooth the barriers between labor education and vocational education, innovation and entrepreneurship education, and realize the effective connection of the education system.

\subsubsection{Course Evaluation Management}

A complete education system not only requires a high-quality faculty and education and teaching level, but also a scientific teaching evaluation system so that the school can make appropriate adjustments based on the evaluation of students. The first is to issue a teaching opinion form to students at the end of the semester, to investigate the effectiveness of labor education and teaching in the current semester, and to continuously modify and improve the labor education system based on the opinions and demands of students, so as to promote the improvement and promotion of labor education; the second is to establish and improve the self-evaluation and mutual evaluation of teachers in labor education, promote each other and make progress together in the evaluation of the subject group; the third is to introduce a third-party structure to conduct a comprehensive and professional assessment of school labor education, form rectification opinions and suggestions, and take multiple measures to promote the improvement of the quality and level of labor education in higher vocational colleges.

\section{CONCLUSION}

As a hot and painful problem of the current vocational education reform and development, labor education needs to be solved urgently. At present, labor education is deeply practiced in higher vocational colleges in Guangdong, and many good practical results have been formed, and there are also many problems. Therefore, the researchers conduct investigation on the implementation of labor education in Guangdong vocational colleges, find the existing pain points and difficulties, analyze the causes, and draw conclusions, and then put forward targeted solutions and strategies, which are of great significance for promoting the reform and development of labor education in Guangdong vocational colleges, improving the labor literacy and comprehensive quality of vocational students, and implementing the fundamental task of strengthening moral education and cultivating people.

\section{AUTHORS' CONTRIBUTIONS}

Xinying Li and Xiaoling Liu are responsible for experimental design, Penghao Li analysed data, Weibo Qiu wrote the manuscript and contributed to revising and editing.

\section{REFERENCES}

[1] Li Ying, An Analysis of the Cultivation Path of College Students' Responsible Spirit [J]. Literature Education, 2020(04). (in Chinese)

[2] Xinhua News Agency, Opinions of the Central Committee of the CPC and the State Council on Comprehensively Strengthening Labor Education in Universities, Middle Schools and Primary Schools in the New Era $[\mathrm{J}]$. Gazette of the State Council of the People's Republic of China, 2020(04). (in Chinese)

[3] Ren Ping, The Structure and Characteristics of the Curriculum of Labor Teacher Education in 
Germany and Its Inspiration - Taking Technical University of Berlin as an Example [J]. Journal of Educational Science of Hunan Normal University, 2020, 19(05): 91-99. (in Chinese)

[4] Ren Ping, He Yang, From "Labor School" to "Integration of General and Vocational Education" - The Value Transmutation, Characteristics and Enlightenment of the Construction of Labor Education Curriculum in Germany [J]. Global Education, 2020, 49(10): 114-128. (in Chinese)

[5] Che Lina, Deng Haiyun, On Contemporary College Students' Biased Labor Concept and Educational Cultivation [J]. Journal of Shenyang Normal University (Social Science Edition), 2020, 44(05): 102-108. (in Chinese)

[6] Zhao Zaojun, Research on the Fusion of College Students' Labor Education and Responsibility Cultivation [J]. Taste \& Classic, 2020(09): 69-71. (in Chinese) 